\title{
Clinical option of pemetrexed-based versus paclitaxel-based first-line chemotherapeutic regimens in combination with bevacizumab for advanced non-squamous non-small-cell lung cancer and optimal maintenance therapy: evidence from a meta-analysis of randomized control trials
}

Le-Tian Huang, Rui Cao, Yan-Ru Wang, Li Sun, Xiang-Yan Zhang, Yi-Jia Guo, Jian-Zhu Zhao, Shu-Ling Zhang, Wei Jing, Jun Song, Cheng-Bo Han and Jietao Ma*

\footnotetext{
Abstract

Background: In the era of immunotherapy, it is still unclear which is the best first-line therapy for patients with oncogenic driver negative advanced non-squamous non-small cell lung cancer (NS-NSCLC) who cannot tolerate immunotherapy, or subsequent therapy for patients with oncogenic driver positive NS-NSCLC whose disease progressed on prior targeted therapy. To assess the optimal choice of first-line and maintenance treatment regimens, we performed a meta-analysis of prospective randomized controlled clinical trials (RCTs) of patients with NS-NSCLC on bevacizumab combined with chemotherapy.

Methods: All eligible RCTs comparing pemetrexed-platinum with or without bevacizumab (PP \pm B) and paclitaxelcarboplatin with bevacizumab $(P C+B)$ as a first-line therapy, or comparing bevacizumab plus pemetrexed $(P e m+B)$ and bevacizumab alone (B) as a maintenance treatment for advanced NS-NSCLC, were included after systematically searching web databases and meeting abstracts. The main research endpoints were comparisons of overall survival (OS) and progression-free survival (PFS). The other endpoints were objective response rate (ORR), 1-year PFS rate (PFSR1y) and major grade 3/4 treatment-related adverse events.

* Correspondence: majt@sj-hospital.org

Department of Oncology, Shengjing Hospital of China Medical University,

Shenyang 110022, China

(c) The Author(s). 2021 Open Access This article is licensed under a Creative Commons Attribution 4.0 International License, which permits use, sharing, adaptation, distribution and reproduction in any medium or format, as long as you give appropriate credit to the original author(s) and the source, provide a link to the Creative Commons licence, and indicate if changes were made. The images or other third party material in this article are included in the article's Creative Commons licence, unless indicated otherwise in a credit line to the material. If material is not included in the article's Creative Commons licence and your intended use is not permitted by statutory regulation or exceeds the permitted use, you will need to obtain permission directly from the copyright holder. To view a copy of this licence, visit http://creativecommons.org/licenses/by/4.0/. The Creative Commons Public Domain Dedication waiver (http://creativecommons.org/publicdomain/zero/1.0/) applies to the data made available in this article, unless otherwise stated in a credit line to the data. 
(Continued from previous page)

Results: Data of 3139 patients from six RCTs were incorporated into analyses. Three RCTs were included in an analysis that compared $\mathrm{PP} \pm \mathrm{B}$ and $\mathrm{PC}+\mathrm{B}$ as a first-line therapy for advanced NS-NSCLC. Patients treated with firstline PP $\pm B$ showed similar OS and ORR, but significantly improved PFS (hazard ratio [HR], 0.88) and PFSR1y (risk ratio $[R R], 0.83$ ), as compared to patients treated with $P C+B$ (all $P<0.05$ ). $P P \pm B$ resulted in higher rates of grade $3 /$ 4 anemia and thrombocytopenia, but lower rates of neutropenia, febrile neutropenia, and sensory neuropathy than $P C+B$ (all $P<0.001)$. The other three RCTs were included in an analysis that compared Pem $+B$ and $B$ as a maintenance treatment. Compared with $B, P e m+B$ maintenance treatment resulted in significant improvements in OS (HR, 0.88), PFS (HR, 0.64), and PFSR1y (RR, 0.70), but higher rates of anemia, thrombocytopenia, and neutropenia (all $P<0.001$ ).

Conclusion: Although the first-line PP + B regimen had longer PFS and PFSR1y than the PC + B regimen, no OS difference was observed. Addition of pemetrexed to bevacizumab as maintenance therapy significantly improved OS compared with bevacizumab maintenance alone, but led to more toxicity.

Keywords: Bevacizumab, First-line treatment, Maintenance treatment, Meta-analysis, Non-small-cell lung cancer, Paclitaxel, Pemetrexed

\section{Background}

Lung cancer remains the cancer with the highest incidence and fatality rates worldwide [1]. With the development and clinical application of molecular targeted drugs and immune checkpoint inhibitors, the survival of patients with advanced non-small cell lung cancer (NSCLC) has significantly improved [2, 3]. For patients with oncogenic driver negative non-squamous NSCLC (NS-NSCLC), regimens containing immunotherapy have become a new standard of first-line treatment [4]. Nevertheless, for patients with oncogenic driver (e.g., EGFR, ALK, and ROS1) positive NS-NSCLC whose disease progressed on prior targeted therapy, or patients with oncogenic driver negative NS-NSCLC who cannot tolerate immunotherapy, platinum-based chemotherapy with or without bevacizumab (a monoclonal antibody against vascular endothelial growth factor [VEGF]) remains the recommended first-line or subsequent therapy. Compared with chemotherapy alone, bevacizumab combined with chemotherapy can further prolong progression-free survival (PFS) and overall survival (OS) for patients with NS-NSCLC [5-8]. However, clinicians are still debating the better choice of first-line chemotherapy regimens (pemetrexed+platinum [PP] versus paclitaxel+carboplatin $[\mathrm{PC}]$ ) in combination with bevacizumab.

In addition, in classic studies of AVAPERL and PARA MOUNT, advanced NS-NSCLC patients with disease control after 4 to 6 cycles of first-line induction chemotherapy can benefit from continuation maintenance treatment with bevacizumab (B), pemetrexed (Pem) or bevacizumab in combination with pemetrexed (Pem + B). However, PFS benefits with doublet maintenance did not translate into an OS advantage $[9,10]$. Since two recent trials (COMPASS and EA5508) presented results on single-agent or doublet maintenance therapy at the
2019 American Society of Clinical Oncology meeting $[11,12]$, we conducted a meta-analysis of randomized control trials (RCTs) to assess the optimal first-line and maintenance regimens for NS-NSCLC patients who are assumed to be intolerant to immunotherapy, by comparing the efficacy and toxicity of first-line treatment regimens between $\mathrm{PP} \pm \mathrm{B}$ and $\mathrm{PC}+\mathrm{B}$, and maintenance treatment regimens between Pem $+\mathrm{B}$, Pem, and $\mathrm{B}$.

\section{Methods \\ Search strategy}

We identified eligible trials by an electronic search of the Cochrane library, PubMed, Embase, and Web of Science databases using the following terms: "non-small cell lung cancer," "NSCLC," and "pemetrexed," "bevacizumab," "paclitaxel," and "chemotherapy," "clinical trials," and "maintenance treatment." The search was performed on March 30, 2020. Two independent reviewers screened titles/abstracts and full text articles. The reference lists including related trials and review articles were manually retrieved.

\section{Selection criteria}

The inclusion criteria were as follows: (1) RCTs; (2) Studies that recruited untreated advanced NS-NSCLC patients; (3) Studies that compared cisplatin (or carboplatin) plus pemetrexed with or without bevacizumab $(\mathrm{PP} \pm \mathrm{B})$ to carboplatin plus paclitaxel with bevacizumab $(\mathrm{PC}+\mathrm{B})$ as first-line treatment, or compared the combination of pemetrexed and bevacizumab to pemetrexed or bevacizumab monotherapy as maintenance treatment. (4) Studies included at least one of the followings as main outcome: OS, PFS, objective response rate (ORR), or grade $\geq 3$ treatment-related adverse events (TRAEs). Studies were excluded if they were repeated published 
studies, non-RCT studies, or non-first-line therapy studies.

\section{Data collection and quality assessment}

Characteristics of trials extracted were: first author's name, year of publication, patient characteristics, study name, study design and phase, sample size, treatment regimens of the study and control groups, maintenance regimens, and treatment cycles. Endpoints extracted were median PFS (mPFS), median OS (mOS), ORR, and grade $\geq 3$ TRAEs. Engauge Digitizer 10.8 software (produced by Mark Mitchell 2014; https://github.com/ markummitchell/engauge-digitizer) was used to extract hazard ratio (HR) and 95\% confidence intervals (CI), as well as other details (such as numbers at risk) from survival curves if no detailed HR values or numbers at risk were given. Trial quality was assessed with the methods recommended by the Cochrane Collaboration for assessing risk of bias [13]. The criteria used for quality assessment were randomization sequence generation, allocation concealment, blinding of participants and personnel, blinding of outcome assessment, incomplete outcome data, selective reporting, and other biases. Each item was categorized as having high, low, or unclear risk. Sensitivity analysis was performed for the primary outcome with the leave-one-out approach.

\section{Statistical analysis}

The meta-analysis was performed using STATA 12.0 (StataCorp, College Station). Analyses were stratified by trial. We compared the efficacy of each treatment regimen during the induction and maintenance phases. The evaluation included OS, PFS, ORR, and TRAEs. OS was evaluated from the beginning of randomized therapy until death due to any cause. PFS was defined as the beginning of randomized therapy until first event (progression or death from any cause). PFS and OS were expressed as HRs. The ORR, PFSR1y, and the rate of grade $\geq 3$ TRAEs were expressed as risk ratios (RRs). All $p$-values were two-sided and were considered statistically significant at the 0.05 level. Heterogeneity was assessed with $\mathrm{X}^{2}$ test $(\alpha=0.1)$ and $\mathrm{I}^{2}$ statistics. When statistics heterogeneity did not exist among studies $\left(P>0.10, \mathrm{I}^{2}<\right.$ $50 \%)$, we used a fixed-effect model; if heterogeneity did exist $\left(P<0.10, \mathrm{I}^{2}>50 \%\right)$, we found the cause and changed to a random-effect model.

\section{Results}

\section{Characteristics of included trials}

Based on the inclusion and exclusion criteria, six RCTs $[9,11,12,14-16]$, including 3144 NS-NSCLC patients were included in this meta-analysis. The baseline characteristics of the included studies are in Tables 1 and 2 . Among them, three trials [14-16] were included in analysis comparing first-line treatment regimens between $\mathrm{PP} \pm \mathrm{B}$ and $\mathrm{PC}+\mathrm{B}$. Three other trials $[9,11,12]$ were included for analysis to compare maintenance regimens between Pem $+B$ and $B$. The flow diagram of the literature retrieval and selection is in Fig. 1.

\section{Comparisons of first-line therapy between $\mathrm{PP} \pm \mathrm{B}$ and $\mathrm{PC}+\mathrm{B}$}

Three RCTs including 1418 patients were used to compare the efficacy and safety of $\mathrm{PP} \pm \mathrm{B}$ and $\mathrm{PC}+\mathrm{B}[14-$ 16], in which $P P+B$ and $P P$ subgroups were compared with $\mathrm{PC}+\mathrm{B}$. Indirect comparisons between subgroups of $\mathrm{PP}+\mathrm{B}$ and $\mathrm{PP}$ were also analyzed.

\section{Efficacy}

The results of efficacy comparison are in Fig. 2. Compared with $\mathrm{PC}+\mathrm{B}, \mathrm{PP} \pm \mathrm{B}$ showed a significant benefit in mPFS (HR $0.88 ; 95 \% \mathrm{CI}, 0.78$ to $0.99 ; P=0.04$ ) and PFSR1y (RR 0.83; 95\% CI, 0.74 to $0.93 ; P=0.001$ ), no significant differences were seen in mOS (HR 1.01; 95\% CI, 0.89 to $1.14 ; P=0.863$ ), and ORR (RR $1.02 ; 95 \% \mathrm{CI}$, 0.92 to $1.15 ; P=0.675$ ) between the two groups. We also calculated pooled mPFS and mOS using a weighted average of single study medians because of insufficient data on $95 \% \mathrm{CI}$ values [17]. For subgroups of $\mathrm{PP} \pm \mathrm{B}$ vs. $\mathrm{PC}+\mathrm{B}, \mathrm{mPFS}$ was 5.77 vs. 5.80 months and mOS was 12.16 vs. 13.04 months.

In the subgroup analysis, compared with $\mathrm{PC}+\mathrm{B}$ group, a PP + B group showed improved mPFS (HR 0.83; 95\% CI, 0.71 to 0.97 ) and PFSR1y (RR 0.77; 95\% CI, 0.68 to 0.89) (all $P<0.05$ ), but no significant difference in ORR and mOS was observed between the two groups. A PP subgroup showed no advantage compared with a $\mathrm{PC}+\mathrm{B}$ group for any parameter. Indirect comparisons found no significant differences between $\mathrm{PP}+\mathrm{B}$ and PP in mPFS $(P=0.36)$, PFSR1y $(P=0.11)$, mOS $(P=0.83)$, or ORR $(P=0.41)$.

\section{Safety}

The most common grade $\geq 3$ TRAEs were hematologic toxicities, hypertension, and sensory neuropathy. Compared with $\mathrm{PC}+\mathrm{B}, \mathrm{PP} \pm \mathrm{B}$ had a significantly higher risk of anemia (RR 1.75; 95\% CI, 1.58 to $1.95 ; P<0.001$ ) and thrombocytopenia (RR 1.70; 95\% CI, 1.47 to $1.96 ; P<$ 0.001 ), but a significantly lower risk of neutropenia (RR 0.67 ; $95 \% \mathrm{CI}, 0.59$ to $0.77 ; P=0.000$ ), febrile neutropenia (RR 0.47; 95\% CI, 0.25 to $0.90 ; P=0.023$ ), and sensory neuropathy (RR $0.21 ; 95 \% \mathrm{CI}, 0.06$ to $0.76 ; P=0.017$ ). No significant differences were seen in hypertension $(P=0.117)$ or drug-related death $(P=0.491)$ between the two groups (Table 3 ). 


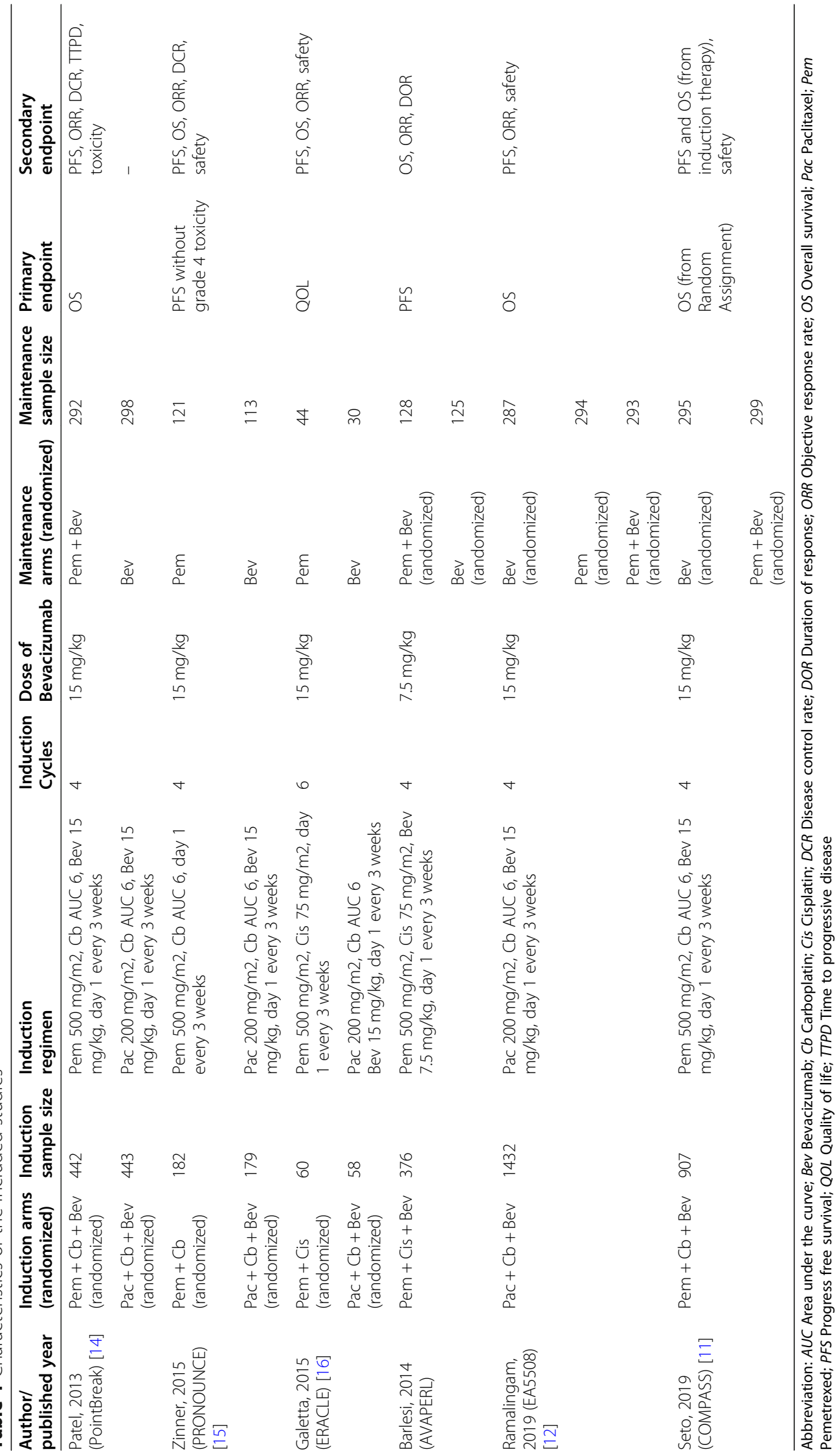


Table 2 Clinicopathological characteristics of the included patients

\begin{tabular}{|c|c|c|c|c|c|c|c|}
\hline Study & Randomized arms & Age, Median (y) & Stage IV (\%) & Male (\%) & ECOG PS 1 (\%) & Never Smoker (\%) & $\begin{array}{l}\text { Adenocarcinoma } \\
\text { (\%) }\end{array}$ \\
\hline \multirow[t]{2}{*}{ PointBreak } & $P P+B$ & 64.6 & $89.8 \%$ & $53.2 \%$ & $56.1 \%$ & $10.6 \%$ & $80.1 \%$ \\
\hline & $P C+B$ & 64.9 & $90.1 \%$ & $53.3 \%$ & $55.6 \%$ & $12.5 \%$ & $78.3 \%$ \\
\hline \multirow[t]{2}{*}{ PRONOUNCE } & PP & 65.8 & $99.5 \%$ & $57.7 \%$ & $52.7 \%$ & $19.9 \%$ & $83.5 \%$ \\
\hline & $P C+B$ & 65.4 & $100.0 \%$ & $58.1 \%$ & $53.1 \%$ & $3.9 \%$ & $76.5 \%$ \\
\hline \multirow[t]{2}{*}{ ERACLE } & PP & 60.0 & $95.0 \%$ & $70.0 \%$ & $22.0 \%$ & $22.0 \%$ & $97.0 \%$ \\
\hline & $P C+B$ & 62.0 & $93.0 \%$ & $78.0 \%$ & $21.0 \%$ & $28.0 \%$ & $97.0 \%$ \\
\hline \multirow[t]{2}{*}{ AVAPERL } & Pem + B & 60.0 & $94.4 \%$ & $57.6 \%$ & $46.0 \%$ & $24.8 \%$ & $85.6 \%$ \\
\hline & B & 60.0 & $89.2 \%$ & $56.7 \%$ & $55.6 \%$ & $26.1 \%$ & $91.7 \%$ \\
\hline \multirow[t]{3}{*}{ EA5508 } & B & 65.0 & $93.0 \%$ & $49.0 \%$ & $57.0 \%$ & $10.0 \%$ & $91.0 \%$ \\
\hline & Pem & 63.0 & $93.0 \%$ & $49.0 \%$ & $54.0 \%$ & $11.0 \%$ & $88.0 \%$ \\
\hline & Pem + B & 64.0 & $93.0 \%$ & $49.0 \%$ & $55.0 \%$ & $11.0 \%$ & $91.0 \%$ \\
\hline \multirow[t]{2}{*}{ COMPASS } & Pem + B & 65.0 & $92.2 \%$ & $73.9 \%$ & $38.5 \%$ & $24.7 \%$ & $96.7 \%$ \\
\hline & B & 65.0 & $90.4 \%$ & $70.8 \%$ & $42.0 \%$ & $20.0 \%$ & $96.3 \%$ \\
\hline
\end{tabular}

Abbreviation: $P P \pm B$ Pemetrexed-platinum with or without bevacizumab; $P C+B$ Paclitaxel-carboplatin with bevacizumab; Pem $+B$ Pemetrexed and bevacizumab; $B$ Bevacizumab; ECOG PS Eastern Cooperative Oncology Group Performance Status

\section{Comparisons of maintenance treatment between Pem $+B$, Pem and $B$}

Three RCTs including 1726 patients were used to compare the efficacy and safety of Pem $+B$ and B maintenance $[9,11,12]$. Two RCTs used a continuation maintenance regimen in the study design $[9,11]$, and one study used continuation and switch maintenance regimens [12]. Indirect comparisons between Pem $+B$ versus Pem maintenance and between Pem versus $B$ maintenance were also analyzed.

\section{Efficacy}

The results of efficacy comparison are in Fig. 3. Compared with $\mathrm{B}$ alone maintenance, Pem $+\mathrm{B}$ maintenance showed significant benefit in mPFS (HR 0.64; 95\% CI, 0.57 to $0.72 ; P<0.001$ ), PFSR1y (RR $0.70 ; 95 \% \mathrm{CI}, 0.63$ to $0.77 ; P<0.001$ ), and $\mathrm{mOS}$ (HR $0.88 ; 95 \% \mathrm{CI}, 0.78$ to $1.00 ; P=0.05$ ). The mPFS and mOS (calculated using a weighted average of the single study medians) in subgroups Pem + B vs. B were 6.73 vs. 4.03 months and 19.39 vs. 16.36 months, respectively [17]. In subgroup analysis, compared with B maintenance, neither Pem + B continuation maintenance nor Pem $+B$ switch maintenance showed obvious differences in mOS.

Indirect comparisons showed that mPFS $(P=0.024)$ and PFSR1y (odds ratio [OR] 0.57; 95\% CI, 0.34 to 0.95 ; $P=0.03$ ) were significantly improved in a Pem $+\mathrm{B}$ maintenance group compared with a Pem maintenance group, but with no significant difference in mOS between the two groups $(P=0.855)$. Pem maintenance showed no benefit compared with B maintenance through indirect comparison of PFSR1y (OR 1.22; 95\% CI, 0.76 to $1.95 ; P=0.41$ ).

\section{Safety}

The most common grade $\geq 3$ TRAEs were hematologic toxicities and hypertension. The risk of anemia (RR 1.75; 95\% CI, 1.46 to $2.09 ; P<0.001$ ), neutropenia (RR 1.95; 95\% CI, 1.80 to $2.12 ; \mathrm{P}<0.001$ ), or thrombocytopenia (RR 1.88; 95\% CI, 1.55 to $2.28 ; \mathrm{P}<0.001$ ) were significantly higher in a Pem $+\mathrm{B}$ maintenance group than in a $B$ alone maintenance group. No significant difference was observed in hypertension $(P=0.864)$ between the two groups (Table 4).

\section{Quality of included studies and publication bias}

The risk of bias assessment of the included RCTs was low and is shown in Table 5; all studies were of high quality. To minimize publication bias, we executed strict inclusion criteria for selected papers and detected publication bias by several methods. No substantial asymmetry was found by visual inspection of the funnel plots. An Egger linear regression test and Begg rank correlation test also found no evidence of publication bias. Sensitivity analyses were conducted on PFS and OS to assess the heterogeneity in the first-line and maintenance phases. No significant heterogeneity in PFS or OS from any study was found.

\section{Discussion}

Chemotherapy combined with immunotherapy has become the current standard care for patients with negative oncogenic drivers regardless of squamous or nonsquamous NSCLC or programmed death ligand 1 (PDL1) expression level [18]. However, chemotherapy plus bevacizumab is still an important first-line treatment option for patients with oncogenic driver negative NS- 


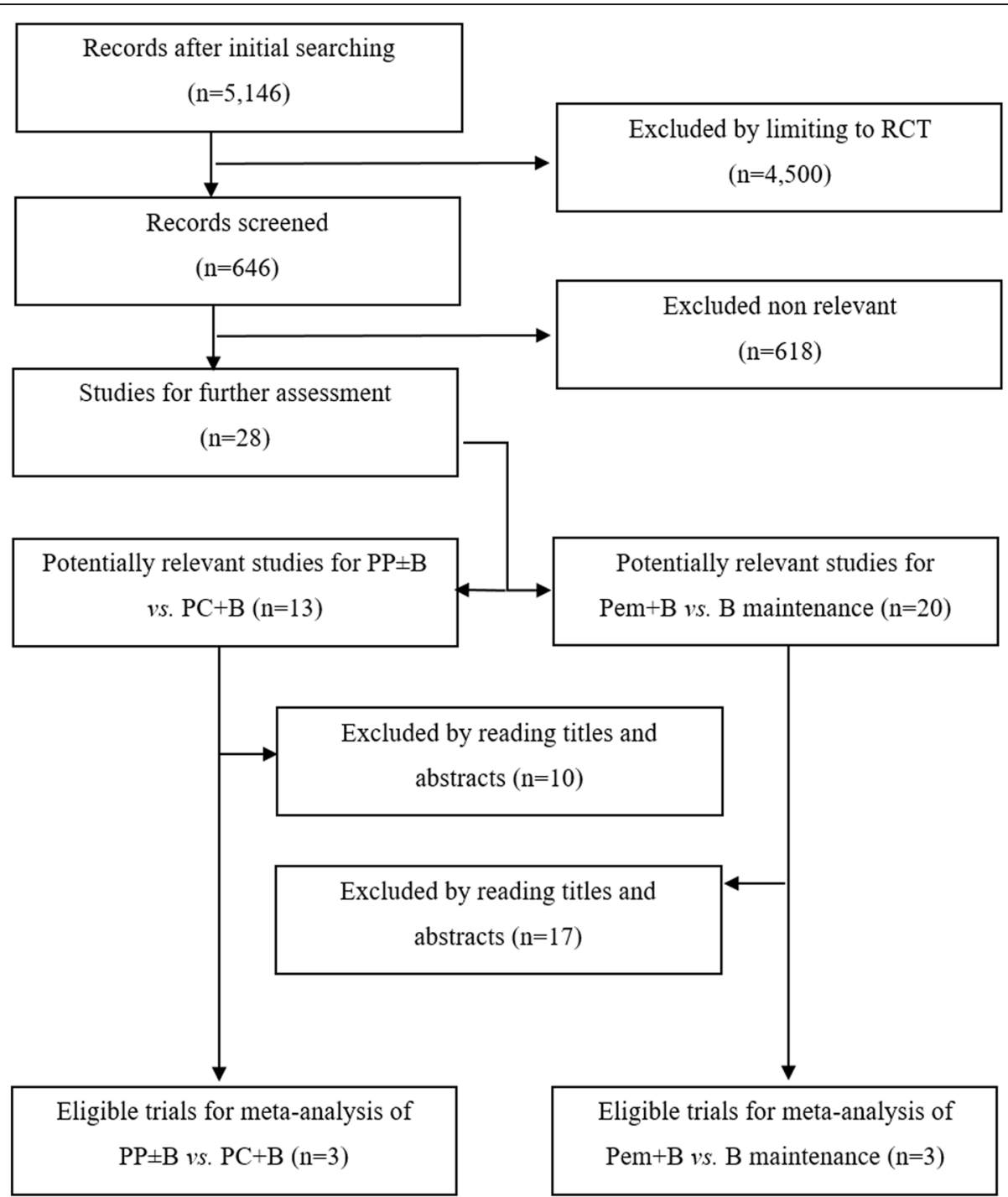

Fig. 1 Overview of study search and selection. A list of excluded papers after reading titles and abstracts can be found in additional file 1

NSCLC who cannot tolerate immunotherapy, and is also a subsequent treatment for patients with oncogenic driver positive NS-NSCLC whose disease progressed on prior targeted therapy. Our study enhances understanding of the rational option of first-line chemotherapy regimens in combination with bevacizumab and the subsequent optimal maintenance therapy for these advanced NS-NSCLC cases. In view of the inclusion of the latest large-sample RCTs and strict inclusion criteria, this meta-analysis thus answers some controversial questions that have not been solved in previous studies.

One question is which first-line chemotherapy regimen (pemetrexed- versus paclitaxel-based) is a better choice when used in combination with bevacizumab. Bevacizumab combined with platinum-based doublet chemotherapy shows clinical benefits for advanced NSNSCLC in multiple RCTs, with mPFS of 6.2-9.2 months and $\mathrm{mOS}$ of $12.3-24.3$ months [5-8]. A meta-analysis showed comparable efficacy for taxane and non-taxane regimens in combination with bevacizumab for treatment of patients with NS-NSCLC. For taxane and nontaxane groups, respective weighted mOS was 14.4 and 13.7 months $(P=0.5)$, mPFS was 6.93 and 6.99 months $(P=0.61)$, and ORR was 41 and $39 \%(P=0.65)$ [19]. Our meta-analysis found that $\mathrm{PP} \pm \mathrm{B}$ had a significant benefit for PFS and PFSR1y, but no difference in OS and ORR between $\mathrm{PP} \pm \mathrm{B}$ and $\mathrm{PC}+\mathrm{B}$. For subgroup comparisons with $\mathrm{PC}+\mathrm{B}, \mathrm{PP}+\mathrm{B}$ had significant benefits for PFS and PFSR1y, but not OS. The negative OS outcome may be attributed to the subsequent maintenance treatment options. Among three studies included for comparison of first-line treatments, PRONOUNCE and ERACLE studies used Pem alone as maintenance therapy; only the PointBreak study used Pem + B maintenance [14-16]. In 


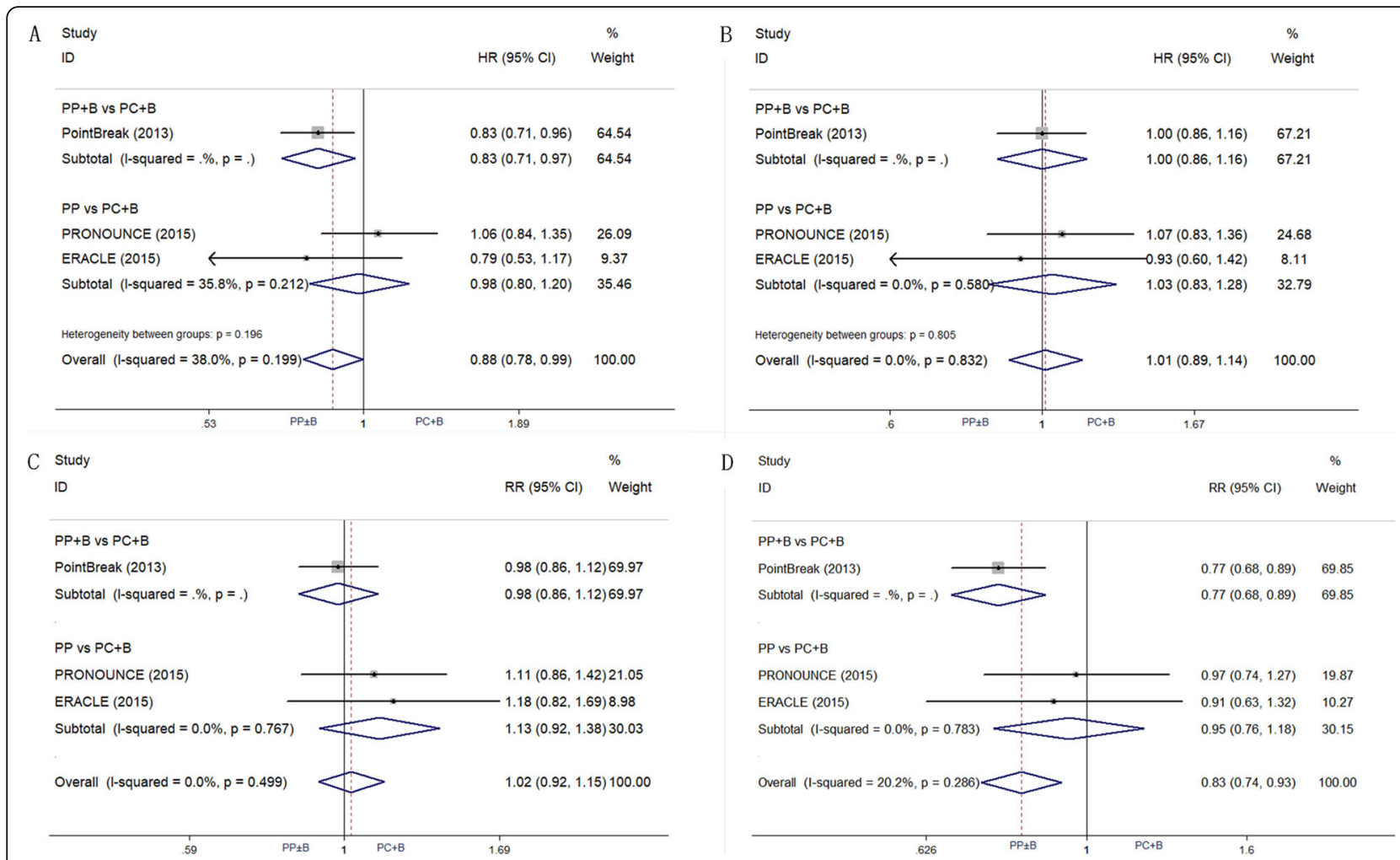

Fig. 2 Efficacy comparison of first-line therapy between PP \pm B and PC + B. a. mPFS; b. mOS; c. ORR; d. PFSR1y. Abbreviations: PP $\pm B$, pemetrexedplatinum with or without bevacizumab; $P C+B$, paclitaxel-carboplatin with bevacizumab; $\mathrm{MPFS}$, median progression-free survival; mOS, median overall survival; ORR, objective response rates; PFSR1y, 1-year PFS rate

our meta-analysis, the two groups had different grade 3/ 4 toxicity profiles. In the PP \pm B group, the risk of severe anemia was 1.75 times and the risk of thrombocytopenia was 1.7 times that in the $\mathrm{PC}+\mathrm{B}$ group. In the $\mathrm{PC}+\mathrm{B}$ group, the risk of severe sensory neuropathy was 4.76 times and the risk of febrile neutropenia was 2.13 times that in the PP \pm B group (Table 3). Since we saw no significant difference in OS between the two groups, the tolerance of patients to different drug toxicities should be considered when choosing first-line chemotherapies. That is, the choice of first-line chemotherapy mainly depends on differences in toxicity profiles.

The second question is which maintenance therapy (B versus $\mathrm{Pem}+\mathrm{B}$ ) is preferred. Maintenance therapy has emerged as a confirmed treatment strategy for advanced NSCLC. For NS-NSCLC patients, Pem + B in combination or as a single drug as a maintenance therapy is shown to be beneficial for survival $[9,10,14,20]$. Even though Pem + B

Table 3 Summary of forest plot for TRAEs (PP $\pm B$ vs. $P C+B)$

\begin{tabular}{|c|c|c|c|c|c|c|}
\hline TRAEs & $\begin{array}{l}\mathrm{PP} \pm \mathrm{B} \\
\mathrm{n} / \mathrm{N}(\%)\end{array}$ & $\begin{array}{l}\mathrm{PC}+\mathrm{B} \\
\mathrm{n} / \mathrm{N}(\%)\end{array}$ & $\begin{array}{l}\text { Heterogeneity } \\
1^{2}\end{array}$ & Heterogeneity $P$ value & RR (95\% Cl) & $P$ value \\
\hline Drug-related deaths & 9/684 (1.3\%) & 13/680 (1.9\%) & $0 \%$ & 0.845 & $0.84(0.52,1.37)$ & 0.491 \\
\hline \multicolumn{7}{|l|}{ Grade 3/4 TRAEs } \\
\hline Anemia & $\begin{array}{l}97 / 684 \\
(14.2 \%)\end{array}$ & 23/680 (3.4\%) & $2.3 \%$ & 0.359 & $1.75(1.58,1.95)$ & 0.000 \\
\hline Hypertension & $\begin{array}{l}15 / 684 \\
(2.2 \%)\end{array}$ & 29/680 (4.3\%) & $0 \%$ & 0.546 & $0.73(0.49,1.08)$ & 0.117 \\
\hline Neutropenia & $161 / 684(23.5 \%)$ & 267/680 (39.3\%) & $1.0 \%$ & 0.364 & $0.67(0.59,0.77)$ & 0.000 \\
\hline Thrombocytopenia & 144/684 (21.1\%) & $42 / 680(6.2 \%)$ & $25.3 \%$ & 0.262 & $1.70(1.47,1.96)$ & 0.000 \\
\hline Sensory neuropathy & $1 / 684(0.1 \%)$ & 26/680 (3.8\%) & $0 \%$ & 0.384 & $0.21(0.06,0.76)$ & 0.017 \\
\hline Febrile neutropenia & 6/684 (0.9\%) & $22 / 680(3.2 \%)$ & $0 \%$ & 0.875 & $0.47(0.25,0.90)$ & 0.023 \\
\hline
\end{tabular}

Abbreviation: $P P \pm B$ Pemetrexed-platinum with or without bevacizumab; $P C+B$ paclitaxel-carboplatin with bevacizumab; $R R$ Risk ratio; TRAEs Treatment-related adverse events 


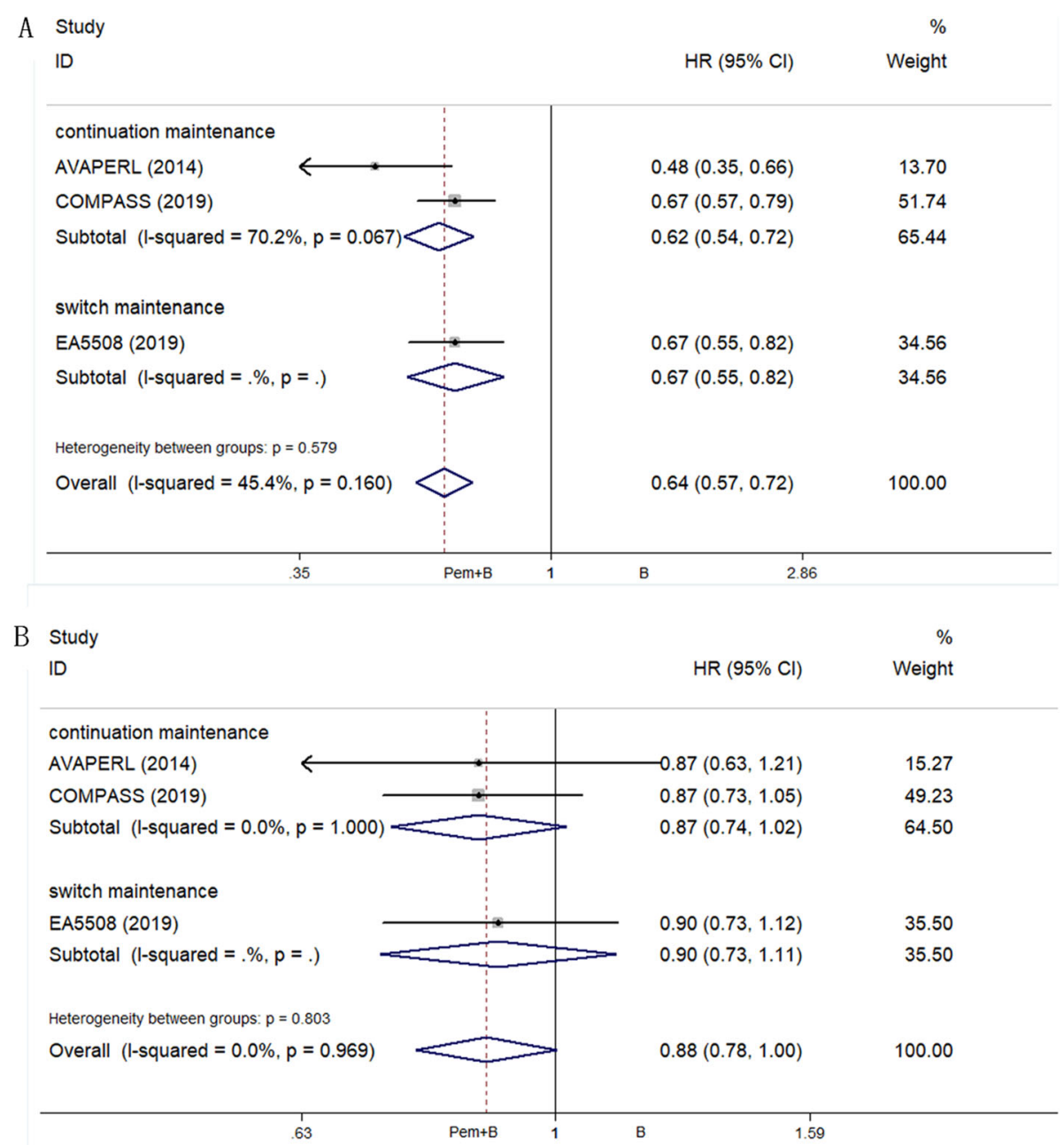

C Study

ID

$\mathrm{RR}(95 \% \mathrm{Cl}) \quad$ Weight

\begin{tabular}{|c|c|c|}
\hline continuation maintenance & & \\
\hline AVAPERL (2014) & $0.72(0.56,0.92)$ & 17.28 \\
\hline COMPASS (2019) & $0.71(0.60,0.84)$ & 38.76 \\
\hline Subtotal $(I-$ squared $=0.0 \%, p=0.956$ & $0.71(0.62,0.81)$ & 56.04 \\
\hline switch maintenance & & \\
\hline EA5508 (2019) & $0.68(0.58,0.79)$ & 43.96 \\
\hline Subtotal (I-squared $=. \%, p=)$. & $0.68(0.58,0.79)$ & 43.96 \\
\hline Overall (I-squared $=0.0 \%, p=0.886$ ) & $0.70(0.63,0.77)$ & 100.00 \\
\hline
\end{tabular}

Fig. 3 Efficacy comparison of maintenance therapy between Pem + B and B. a. mPFS; b. mOS; c. ORR. Abbreviations: Pem + B, pemetrexed and bevacizumab; $B$, bevacizumab; mPFS, median progression-free survival; mOS, median overall survival; ORR, objective response rates

showed significant benefits in PFS compared to monotherapy B maintenance, four previous studies did not recommend Pem $+\mathrm{B}$ as a standard maintenance regimen because of the lack of OS benefits and higher toxicity $[9,11,12,14]$. Combining two recent RCTs [11, 12], our meta-analysis showed not only an improvement in PFS with Pem $+\mathrm{B}$ 
Table 4 Summary of forest plot for grade 3/4 TRAEs (Pem + B vs. B maintenance)

\begin{tabular}{|c|c|c|c|c|c|c|}
\hline $\begin{array}{l}\text { Grade } 3 / 4 \\
\text { TRAEs }\end{array}$ & $\begin{array}{l}\text { Pem + B } \\
\text { n/N (\%) }\end{array}$ & $\begin{array}{l}\text { B } \\
\text { n/N (\%) }\end{array}$ & Heterogeneity $I^{2}$ & Heterogeneity $P$ value & RR $(95 \% \mathrm{Cl})$ & $P$ value \\
\hline Anemia & $35 / 620(5.6 \%)$ & $7 / 707(1.0 \%)$ & $41.8 \%$ & 0.179 & $1.75(1.46,2.09)$ & 0.000 \\
\hline Hypertension & 97/620 (15.6\%) & 98/707 (13.9\%) & $60.8 \%$ & 0.078 & $1.02(0.78,1.34)$ & 0.864 \\
\hline Neutropenia & $81 / 620(13.1 \%)$ & 6/707 (0.8\%) & $0 \%$ & 0.872 & $1.95(1.80,2.12)$ & 0.000 \\
\hline Thrombocytopenia & $14 / 620(2.3 \%)$ & 1/707 (1.0\%) & $10.4 \%$ & 0.291 & $1.88(1.55,2.28)$ & 0.000 \\
\hline
\end{tabular}

Abbreviation: Pem $+B$ Pemetrexed and bevacizumab; $B$ Bevacizumab; RR Risk ratio; TRAEs Treatment-related adverse events

maintenance, but also a benefit in OS $(P=0.05)$, and the latter was demonstrated for the first time. The PointBreak study showed a longer OS for Pem + B maintenance than B alone, but that trial could not be included in our metaanalysis, because the timepoint after random assignment was different from those in the other trials [14]. Although the addition of pemetrexed to bevacizumab as a maintenance therapy $(\mathrm{Pem}+\mathrm{B})$ can moderately improve survival, we still need to be cautious, as doublet maintenance leads to more toxicities, especially hematological toxicity. In our meta-analysis, the risk of grade 3/4 TRAEs including anemia, thrombocytopenia, and neutropenia were all significantly higher in the Pem $+B$ groups. This may lead to a prolonged treatment interval, poor compliance with maintenance treatment, or even drug-related termination or death. Therefore, we recommend that only patients with NS-NSCLC with controlled disease after 4 to 6 cycles of $\mathrm{PP}+\mathrm{B}$ induction therapy who have not experienced intolerable toxicity receive Pem $+\mathrm{B}$ continuation maintenance therapy whenever possible.

The third question is whether bevacizumab should be added to a PP regimen. Pemetrexed combined with platinum is the preferred frontline chemotherapy for patients with NS-NSCLC in National Comprehensive Cancer Network $(\mathrm{NCCN})$ guidelines [21]. Efficacy of PP $+\mathrm{B}$ has been observed in some trials $[9,11,14,20]$, but no direct prospective comparison has been made between $\mathrm{PP}+\mathrm{B}$ and $\mathrm{PP}$. However, designing prospective trials comparing $\mathrm{PP}+$ $\mathrm{B}$ and PP seems increasingly infeasible. In both the PRONOUNCE and ERACLE study designs, bevacizumab was added to the PC regimen, but not to the PP regimen. Nevertheless, no significant difference in PFS or OS was observed between PP and PC $+B[15,16]$. Our metaanalysis indicated that $\mathrm{PP}+\mathrm{B}$ significantly prolonged $\mathrm{PFS}$, as compared to $\mathrm{PC}+\mathrm{B}$, but no significant differences were seen in any survival data between PP $+\mathrm{B}$ and PP by indirect comparisons. However, the strength of the evidence to clarify this issue remains limited.

Currently, pembrolizumab in combination with chemotherapy is the preferred first-line regimen according to NCCN guidelines for patients with oncogenic driver negative NS-NSCLC and without contraindications to PD-1/ PD-L1 inhibitors, regardless of PD-L1 expression level. Atezolizumab in combination with chemotherapy and bevacizumab is the other recommended regimen [22]. Interestingly, the chemotherapies in these two regimens differ (carboplatin/cisplatin+pemetrexed, and carboplatin+ paclitaxel, respectively). In the future, we should focus on whether bevacizumab is a good partner to combine with chemotherapy and anti-PD-1 immunotherapy (e.g., pembrolizumab) for both first-line and maintenance treatment.

In our meta-analysis, we strictly limited the inclusion criteria to RCTs. However, summary statistics rather than individual patient data were used for each trial, and the studies included were heterogeneous, with varying patient populations and different study designs. For example, EGFR-sensitizing mutation populations were excluded in the COMPASS trial, but not mentioned in the other five trials. This difference may lead to different subsequent line regimens and survival.

\section{Conclusions}

On the basis of the answers to these three questions, we have made preliminary recommendations for first-line

Table 5 Evaluation of risk of bias in the included studies

\begin{tabular}{|c|c|c|c|c|c|c|}
\hline Items & PointBreak 2013 & AVAPERL 2014 & ERACLE 2015 & PRONOUNCE 2015 & COMPASS 2019 & $\begin{array}{l}\text { EA5508 } \\
2019\end{array}$ \\
\hline Randomization sequence generation & low & low & low & low & low & low \\
\hline Allocation concealment & unclear & unclear & unclear & unclear & unclear & unclear \\
\hline Blinding of participants and personnel & high & high & unclear & high & unclear & high \\
\hline Blinding of outcome assessment & high & high & unclear & high & unclear & unclear \\
\hline Incomplete outcome data & high & low & high & low & unclear & low \\
\hline Selective reporting & unclear & unclear & low & low & low & low \\
\hline Other biases & low & unclear & low & low & unclear & low \\
\hline
\end{tabular}


and maintenance treatment strategies for patients with advanced NS-NSCLC with negative drivers who cannot tolerate immunotherapy: i) $\mathrm{PP}+\mathrm{B}$ as first-line therapy is as effective as $\mathrm{PC}+\mathrm{B}$ in patients with advanced NSNSCLC, and the toxicity profile of the two therapies varies. ii) Addition of pemetrexed to bevacizumab as maintenance therapy significantly improved survival, but led to more toxicity. iii) Patients' tolerance and toxicity profiles should be considered when choosing treatment regimens. iv) Treatment with $\mathrm{PP}+\mathrm{B}$ or $\mathrm{PC}+\mathrm{B}$ followed by Pem $+B$ rather than single-drug $B$ or Pem maintenance might be the best choice under the premise of tolerable toxicity.

In addition, a phase III RCT IMpower-150 found that in a subset of EGFR/ALK-positive advanced NS-NSCLC patients whose disease progressed on prior targeted therapy, adding atezolizumab to $\mathrm{PC}+\mathrm{B}$ can significantly improve the survival. Although additional studies on quadruple use focused specifically on this subgroup of patients are still needed, at least for now, the above recommendations may also be applicable for patients with positive oncogenic drivers whose disease progressed on prior targeted therapy.

\section{Abbreviations}

NSCLC: Non-small cell lung cancer; NS-NSCLC: Non-squamous NSCLC; PDL1: Programmed death-ligand 1; RCTs: Randomized controlled clinical trials; VEGF: Vascular endothelial growth factor; $P P \pm B$ : Pemetrexed-platinum with or without bevacizumab; PC + B: Paclitaxel-carboplatin with bevacizumab; Pem + B: Pemetrexed and bevacizumab; TRAEs: Treatment-related adverse events; Cl: Confidence intervals; ORR: Objective response rate; OS: Overall survival; PFS: Progress free survival; PFSR1y: 1-Year PFS rate; HR: Hazard ratio; RR: Risk ratio; NCCN: National comprehensive cancer network

\section{Supplementary Information}

The online version contains supplementary material available at https://doi. org/10.1186/s12885-021-08136-5.

Additional file 1:. A list of excluded papers after reading titles and abstracts.

\section{Acknowledgments}

The authors thank all the medical staff who contributed to the maintenance of the medical record database.

\section{Authors' contributions}

All of the authors have read and approved the final manuscript. LH, JM and $\mathrm{CH}$ conceived and designed the study. $\mathrm{LH}, \mathrm{RC}, \mathrm{YW}, \mathrm{LS}, \mathrm{XZ}$ and $\mathrm{YG}$ took full responsibility for data collecting. LH, JZ, SZ, WJ and JS performed the metaanalysis, systematic review, and drafted the manuscript. $\mathrm{CH}$ and JM helped revise the manuscript.

\section{Funding}

This study was supported by grants from the 345 Talent Project of Shengjing Hospital. The funding bodies played no role in the design of the study and collection, analysis, and interpretation of data and in writing the manuscript.

\section{Availability of data and materials}

The data that support the findings of this study are available from the corresponding author upon reasonable request.

\section{Declarations}

Ethics approval and consent to participate

Not applicable.

\section{Consent for publication}

Not applicable.

\section{Competing interests}

The authors declare no conflict of interest.

Received: 15 July 2020 Accepted: 2 April 2021

Published online: 17 April 2021

\section{References}

1. Bray F, Ferlay J, Soerjomataram I, Siegel RL, Torre LA, Jemal A. Global cancer statistics 2018: GLOBOCAN estimates of incidence and mortality worldwide for 36 cancers in 185 countries. CA Cancer J Clin 2018;68:394-424. https:// doi.org/10.3322/caac.21492, 6.

2. Reck M, Rodriguez-Abreu D, Robinson AG, Hui R, Csoszi T, Fulop A, et al. Updated analysis of KEYNOTE-024: pembrolizumab versus platinum-based chemotherapy for advanced non-small-cell lung cancer with PD-L1 tumor proportion score of 50\% or greater. J Clin Oncol 2019;37:537-546. https:// doi.org/https://doi.org/10.1200/JCO.18.00149, 7.

3. Dong J, Li B, Zhou Q, D Lin, D Huang. Advances in targeted therapy and immunotherapy for Non-Small Cell Lung Cancer based on accurate molecular typing Frontiers in Pharmacology 2019;10:230. https://doi.org/ https://doi.org/10.3389/fphar.2019.00230.

4. Ettinger DS, Wood DE, Aggarwal C, Aisner DL, Akerley W, Bauman JR, et al. NCCN guidelines insights: non-small cell lung cancer, version 1.2020: featured updates to the NCCN guidelines. J Natl Compr Cancer Netw. 2019; 17:1464-1472. https://doi.org/https://doi.org/10.6004/jnccn.2019.0059.

5. Sandler A, Gray R, Perry MC, Brahmer J, Schiller JH, Dowlati A, et al. Paclitaxel-carboplatin alone or with bevacizumab for nonsmall-cell lung cancer. N Engl J Med. 2006;355(24):2542-50. https://doi.org/. https://doi. org/10.1056/NEJMoa061884.

6. Zhou C, Wu YL, Chen G, Liu X, Zhu Y, Lu S, Feng J, He J, Han B, Wang J, Jiang G, Hu C, Zhang H, Cheng G, Song X, Lu Y, Pan H, Zheng W, Yin AY BEYOND: a randomized, double-blind, placebo-controlled, multicenter, phase III study of first-line carboplatin/ paclitaxel plus bevacizumab or placebo in chinese patients with advanced or recurrent nonsquamous nonsmall-cell lung cancer. J Clin Oncol 2015;33:2197-2204. https://doi.org/ https://doi.org/10.1200/JCO.2014.59.4424, 19.

7. Johnson DH, Fehrenbacher L, Novotny WF, Herbst RS, Nemunaitis JJ, Jablons DM, Langer CJ, DeVore III RF, Gaudreault J, Damico LA, Holmgren E, Kabbinavar F Randomized phase II trial comparing bevacizumab plus carboplatin and paclitaxel with carboplatin and paclitaxel alone in previously untreated locally advanced or metastatic nonsmall-cell lung cancer. J Clin Oncol 2004;22:2184-2191. https://doi.org/ https://doi.org/10.12 00/jco.2004.11.022, 11.

8. Niho S, Kunitoh H, Nokihara H, Horai T, Ichinose Y, Hida T, Yamamoto N, Kawahara M, Shinkai T, Nakagawa K, Matsui K, Negoro S, Yokoyama A, Kudoh S, Kiura K, Mori K, Okamoto H, Sakai H, Takeda K, Yokota S, Saijo N, Fukuoka M Randomized phase II study of first-line carboplatin-paclitaxel with or without bevacizumab in Japanese patients with advanced nonsquamous non-smallcell lung cancer. Lung Cancer 2012;76:362-367. https:// doi.org/ https://doi.org/10.1016/j.lungcan.2011.12.005, 3.

9. Barlesi F, Scherpereel A, Rittmeyer A, Pazzola A, Ferrer TN, Kim JH, et al. Randomized phase III trial of maintenance bevacizumab with or without pemetrexed after first-line induction with bevacizumab, cisplatin, and pemetrexed in advanced nonsquamous non-small-cell lung cancer: AVAP ERL (MO22089). J Clin Oncol 2013;31:3004-3011. https://doi.org/ https://doi. org/10.1200/JCO.2012.42.3749, 24.

10. Paz-Ares L, de Marinis F, Dediu M, Thomas M, Pujol JL, Bidoli P, et al. Maintenance therapy with pemetrexed plus best supportive care versus placebo plus best supportive care after induction therapy with pemetrexed plus cisplatin for advanced non-squamous non-small-cell lung cancer (PARAMOUNT): a doubleblind, phase 3, randomised controlled trial. Lancet Oncol. 2012;13(3):247-55. https://doi.org/. https://doi.org/10.1016/S1470-2045(12)70063-3.

11. Seto T, Azuma K, Yamanaka T, Sugawara S, Yoshioka H, Wakuda K, et al. Randomized phase III study of continuation maintenance bevacizumab with 
or without pemetrexed in advanced nonsquamous non-small-cell lung cancer: COMPASS (WJOG5610L). J Clin Oncol. 2019;JCO:19. https://doi.org/ https://doi.org/10.1200/JCO.19.01494

12. Ramalingam SS, Dahlberg SE, Belani CP, Saltzman JN, Pennell NA, Nambudiri GS, McCann JC, Winegarden JD, Kassem MA, Mohamed MK, Rothman JM, Lyss AP, Horn L, Stinchcombe TE, Schiller JH Pemetrexed, bevacizumab, or the combination as maintenance therapy for advanced nonsquamous nonsmall-cell lung cancer: ECOG-ACRIN 5508. J Clin Oncol 2019;37:2360-2367. https://doi.org/ https://doi.org/10.1200/JCO.19.01006, 26.

13. Higgins JP, Altman DG. Assessing risk of bias in included studies. In: Higgins $J P$, Green S, editors. Cochrane handbook for systematic reviews of interventions: Cochrane book series. Chichester: John Wiley \& Sons; 2008. p. 187-241. https://doi.org/10.1002/9780470712184.ch8.

14. Patel JD, Socinski MA, Garon EB, Reynolds CH, Spigel DR, Olsen MR, Hermann RC, Jotte RM, Beck T, Richards DA, Guba SC, Liu J, Frimodt-Moller B, John WJ, Obasaju CK, Pennella EJ, Bonomi P, Govindan R PointBreak: a randomized phase III study of pemetrexed plus carboplatin and bevacizumab followed by maintenance pemetrexed and bevacizumab versus paclitaxel plus carboplatin and bevacizumab followed by maintenance bevacizumab in patients with stage IIIB or IV nonsquamous non-small-cell lung cancer. J Clin Oncol 2013;31:4349. https://doi.org/ https://doi.org/10.1200/JCO.2012.47.9626, 34, 4357.

15. Zinner RG, Obasaju CK, Spigel DR, Weaver RW, Beck JT, Waterhouse DM, Modiano MR, Hrinczenko B, Nikolinakos PG, Liu J, Koustenis AG, Winfree KB, Melemed SA, Guba SC, Ortuzar WI, Desaiah D, Treat JA, Govindan R, Ross HJ PRONOUNCE: randomized, open-label, phase III study of first-line pemetrexed 1 carboplatin followed by maintenance pemetrexed versus paclitaxel 1 carboplatin 1 bevacizumab followed by maintenance bevacizumab in patients ith advanced nonsquamous non-small-cell lung cancer. J Thorac Oncol 2015;10:134-142. https://doi.org/ https://doi.org/10.1 097/JTO.0000000000000366, 1.

16. Galetta D, Cinieri S, Pisconti S, Gebbia V, Morabito A, Borsellino N, Maiello E, Febbraro A, Catino A, Rizzo P, Montrone M, Misino A, Logroscino A, Rizzi D, di Maio M, Colucci G Cisplatin/pemetrexed followed by maintenance pemetrexed versus carboplatin/paclitaxel/bevacizumab followed by maintenance bevacizumab in advanced nonsquamous lung cancer: the GOIM (Gruppo Oncologico Italia Meridionale) ERACLE phase III randomized trial. Clin Lung Cancer 2015;16:262-273. https:/doi.org/ https://doi.org/10.1016/..llc.2014.12.002, 4.

17. Ma JT, Sun J, Sun L, Zhang SL, Huang LT, Han CB. Efficacy and safety of apatinib in patients with advanced nonsmall cell lung cancer that failed prior chemotherapy or EGFR-TKIs: a pooled analysis. Medicine. 2018;97(35): e12083. https://doi.org/. https://doi.org/10.1097/MD.0000000000012083.

18. Cao R, Ma JT, Zhang SL, Sun L, Liu Y, Zhang XY, et al. Rational application of the first-line chemotherapy and immune checkpoint inhibitors in advanced nonsmall cell lung cancer: a meta-analysis. Cancer medicine. 2019;8(11): 5033-46. https://doi.org/. https://doi.org/10.1002/cam4.2407.

19. Socinski MA, Jotte RM, Cappuzzo F, Orlandi F, Stroyakovskiy D, Nogami N, et al. Atezolizumab for first-line treatment of metastatic nonsquamous NSCL C. N Engl J Med. 2018;378(24):2288-301. https://doi.org/. https://doi.org/10.1 056/NEJMoa1716948.

20. Behera M, Pillai RN, Owonikoko TK, Kim S, Steuer C, Chen Z, Saba NF, Belani CP, Khuri FR, Ramalingam SS Bevacizumab in combination with taxane versus non-taxane containing regimens for advanced/metastatic nonsquamous non-small-cell lung Cancer: a systematic review. J Thorac Oncol 2015;10:1142-1147. https://doi.org/ https://doi.org/10.1097/JTO. $0000000000000572,8$.

21. Karayama M, Inui N, Fujisawa T, Enomoto N, Nakamura Y, Kuroishi S, Yokomura K, Koshimizu N, Sato M, Toyoshima M, Shirai T, Masuda M, Yamada T, Imokawa S, Suda T Maintenance therapy with pemetrexed and bevacizumab versus pemetrexed monotherapy after induction therapy with carboplatin, pemetrexed, and bevacizumab in patients with advanced nonsquamous non small cell lung cancer. Eur I Cancer 2016;58:30-37. https:// doi.org/ https://doi.org/10.1016/j.ejca.2016.01.013.

22. Masters GA, Temin S, Azzoli CG, Giaccone G, Baker S Jr, Brahmer JR, et al. Systemic therapy for stage IV non-small-cell lung cancer: American society of clinical oncology clinical practice guideline update. J Clin Oncol 2015;33: 3488-3515. https://doi.org/ https://doi.org/10.1200/JCO.2015.62.1342, 30.

\section{Publisher's Note}

Springer Nature remains neutral with regard to jurisdictional claims in published maps and institutional affiliations.

Ready to submit your research? Choose BMC and benefit from:

- fast, convenient online submission

- thorough peer review by experienced researchers in your field

- rapid publication on acceptance

- support for research data, including large and complex data types

- gold Open Access which fosters wider collaboration and increased citations

- maximum visibility for your research: over $100 \mathrm{M}$ website views per year

At BMC, research is always in progress.

Learn more biomedcentral.com/submissions 